TENDENCIAS

Revista de la Facultad de Ciencias

Económicas y Administrativas.

Universidad de Nariño

ISSN-E 2539-0554

Vol. XXII No. 2 - 2do Semestre 2021

Julio-Diciembre - Páginas 239-263

\title{
IMPACTO SOCIOECONÓMICO Y CULTURAL DEL TURISMO DE SOL Y PLAYA \\ EN EL GOLFO DE MORROSQUILLO 2016 - 2020
}

SOCIOECONOMIC AND CULTURAL IMPACT OF SUN AND BEACH TOURISM IN THE GULF OF MORROSQUILLO 2016 - 2020

\section{IMPACTO SÓCIO-ECONÔMICO E CULTURAL DO TURISMO SOLAR E DE PRAIA NO GOLFO DE MORROSQUILLO 2016 - 2020}

\section{Anddy Katherine Sierra Márquez; Licette Estela Ramos Pérez; Mario Fernando Zubiría Lara}

Especialista en Finanzas, Universidad de Cartagena, Colombia. Docente Programa Administración de Empresas, Universidad Nacional Abierta y a Distancia UNAD. ORCiD: 0000-0002-2992-9812. E-mail: anddy.sierra@unad.edu.co, Colombia.

Especialista en Gerencia Pública, Corporación Universitaria del Caribe CECAR, Colombia. Docente Programa Administración de Empresas, Universidad Nacional Abierta y a Distancia UNAD. ORCiD: 0000-0002-7327-3355. E-mail: licette.ramos@unad.edu.co, Colombia.

Master Business Administrator, Universidad UNAD Florida, USA. Docente Programa Administración de Empresas, Universidad Nacional Abierta y a Distancia UNAD. ORCiD: 00000002-1392-1728. E-mail: mario.zubiria@ unad.edu.co, Colombia.

Recibido: 15 de diciembre de 2020

Aprobado: 31 de marzo de 2021

DOI: https://doi.org/10.22267/rtend.212202.175

\section{Resumen}

El presente artículo es el resultado del estudio titulado, Impacto económico y sociocultural del turismo de sol y playa en la subregión Golfo de Morrosquillo del Departamento de Sucre - 
Colombia 2016 - 2020 y tuvo como objetivo el análisis contextual de dicho impacto a partir de las prácticas y modo de vida de las comunidades o nativos dedicados al turismo. Para ello, se optó por un enfoque cualitativo, bajo un trabajo de campo de tipo fenomenológico que permitió la aplicación de un cuestionario de caracterización económica y sociocultural a una muestra no probabilística conformada por 135 personas cabezas de hogar distribuidos así: Municipio de San Onofre (25), Municipio de Coveñas (38), Municipio de Santiago de Tolú (72). Como resultado se encuentra que el impacto más significativo del turismo de sol y playa sobre las comunidades costeras es el cambio de su vocación productiva. Se concluye entonces que el apoyo al turismo como sector de la economía de la región es fundamental para el mejoramiento de la calidad de vida de las comunidades; en el campo cultural, los nativos identifican sus valores culturales y reconocen en ellos atractivos turísticos y finalmente, en materia social, las precarias condiciones de convivencia, son el obstáculo más relevante en el desarrollo de una industria del trismo de sol y playa efectiva.

Palabras clave: calidad de vida; cultura; socioeconómico; turismo.

JEL: R1; R11; R13; R5; R58

\begin{abstract}
This article is the result of the study entitled, Economic and sociocultural impact of sun and beach tourism in the Gulf of Morrosquillo subregion of the department of Sucre - Colombia, and its objective was the contextual analysis of said impact based on the practices and modes life of the communities or natives dedicated to tourism. For this, a qualitative approach was chosen, under a field work and of a phenomenological type that allowed the application of an economic and sociocultural characterization questionnaire to a non-probabilistic sample made up of 135 heads of household distributed as follows: Municipality of San Onofre (25), Municipality of Coveñas (38), Municipality of Santiago de Tolú (72). As a result, it is found that the most significant impact of sun and beach tourism on coastal communities is the change in their productive vocation. It is concluded then that the support to tourism as a sector of the economy of the region is fundamental for the improvement of the quality of life of the communities. Likewise, it is concluded that, in cultural matters, the natives identify their cultural values and recognize them as tourist attractions.
\end{abstract}


Finally, in social matters, the precarious conditions of coexistence are the most relevant obstacle in the development of an effective trismus and beach industry.

Keywords: quality of life; culture; socioeconomic; sightseeing.

JEL: R1; R11; R13; R5; R58

\section{Resumo}

Este artigo é o resultado do estudo: Impacto econômico e sociocultural do turismo de sol e praia na sub-região do Golfo de Morrosquillo do Departamento de Sucre - Colômbia, que teve como objetivo a análise contextual desse impacto a partir das práticas e estilos de vida das comunidades ou nativos dedicados ao turismo. Para isso, optou-se por uma pesquisa qualitativa e de tipo fenomenológico que permitiu a aplicação de um questionário de caracterização econômica e sociocultural a uma amostra não probabilística composta por 135 chefes de família assim distribuídos: Município de San Onofre (25), Município de Coveñas (38), Município de Santiago de Tolú (72). Nos resultados, verificou-se que o impacto mais significativo do turismo de sol e praia nas comunidades costeiras é a mudança na sua vocação produtiva. Desea forma, concluiu-se que o apoio ao turismo como parte da economia da região é fundamental para melhorar a qualidade de vida das comunidades. Da mesma forma, conclui-se que, em questões culturais, os indígenas identificam seus valores culturais e os reconhecem como atrações turísticas. Por fim, em matéria social, as precárias condições de convivência são o obstáculo mais relevante ao desenvolvimento de um trismo e indústria de praia eficazes.

Palavras-chave: qualidade de vida; cultura; socio-econômico; passeio turístico.

JEL: R1; R11; R13; R5; R58

\section{Introducción}

El turismo de sol y playa ha sido históricamente una de las manifestaciones turísticas más comunes y espontáneas de la sociedad, el aprovechamiento del recurso natural asociado al paisaje constituye las condiciones básicas del escenario del servicio. No obstante, en las últimas tres décadas el mercado turístico manifiesta una creciente tendencia a nuevas búsquedas de satisfacción y 
expectativas por parte de sus clientes, lo cual ha hecho que aumente su consumo y por ende la demanda de recursos y talento humano empleado para tal fin.

Por lo tanto, Amaya et al. (2017) plantea que, el auge del turismo de sol y playa, trae consigo el aumento de la dinámica socioeconómica y cultural vinculada a la actividad, comprometiendo familias y comunidades enteras que han migrado hacia el servicio turístico y abandonado viejos oficios como la pesca y la agricultura y explotando la riqueza forestal, de fauna y del suelo como fuente de sustento alrededor de la llegada de miles de visitantes o turistas.

De esta manera, García y Albuquerque (2003) definen el turismo de sol y playa como aquella actividad anclada a las zonas costeras o de litoral y que se caracteriza por condiciones de relieve y climáticas favorables. Por lo tanto, la actividad dependerá en gran medida de las condiciones naturales de la zona, pero no por ello la demanda dejará de requerir infraestructura, servicio, productos y programas de diversión organizados por los prestadores formales o informales de dicha zona.

Romero (2017) indica que, en Colombia, principalmente en la zona del litoral del océano atlántico, existen muchos lugares que reúnen las condiciones para el turismo de sol y playa, lo cual no es frecuente en la zona del litoral pacífico, donde las condiciones climáticas y de relieve no son favorables y atractivas para el turista o visitante. Por lo tanto, es el caribe colombiano, la zona costera por excelencia para este tipo de turismo raizal, en el cual se encuentra el Departamento de Sucre, dueño de ciento cuatro (104) kilómetros de contacto entre el continente y el mar Caribe, en lo que se ha denominado la subregión del golfo de Morrosquillo.

A manera de caracterización territorial, Aguilera (2005) da a conocer que esta subregión se encuentra ubicada entre el Valle de la Sierra Flor y el Mar Caribe y comprende el litoral del Departamento de Sucre, y parte del litoral del Departamento de Córdoba con una extensión de $1.886 \mathrm{~km}^{2}$ y constituye el 17,6\% del Departamento de Sucre, está conformada por los Municipios de San Onofre, Palmito, Tolú, Toluviejo y Coveñas, siendo las cabeceras municipales de Santiago de Tolú y Coveñas, los cuales, según la Alcaldía de Tolú (2014) son centros turísticos por 
excelencia que han venido transformado su economía y cultura por cuenta de una vocación turística de sol y playa reconocida a nivel nacional e internacional.

Mercado et al. (2015) Revelan que, ésta vocación ha motivado la transformación de las tareas productivas de buena parte de las comunidades costeras, hacia la realización de actividades vinculadas al turismo de sol y playa de donde extraen su sustento, en labores formales como la hotelería y hospedaje, el servicio de restaurante y bar, servicios inmobiliarios, el comercio y los paquetes turísticos por parte de agencias legalmente constituidas. Así mismo, los nativos y sus familias se vinculan por medio de actividades informales como el servicio de guía y la venta ambulante de productos autóctonos o mercancías manufacturadas.

Lo anterior refleja un profundo impacto de orden económico, social y cultural en dichas comunidades, que ha transformado radicalmente los modos de vida de los nativos, atrayendo al tiempo la inversión y la colonización de foráneos de otras regiones del país y del exterior. Ortiz y Peralta (2019) manifiestan que, quienes han construido y dado apertura a nuevas formas de comercialización y explotación de los recursos naturales y su atractivo, dejando en ocasiones relegado al habitante raizal que ha convivido por siglos frente al mar, la brisa y bajo el sol del Caribe.

Por lo tanto, el presente estudio, se constituye en un aporte significativo al entendimiento del impacto socioeconómico y cultural de la práctica de un modelo de turismo de sol y playa en la zona del Golfo de Morrosquillo, toda vez que incide directamente a las comunidades costeras que encuentran su sustento en dicha actividad. Basados en los aportes de Beltrán y Gómez (2018) para el Departamento de Sucre, la explotación del turismo de forma sostenible, más que una alternativa es una necesidad y la puesta en escena desde la investigación y la academia de su dinámica social, económica y cultural, haciendo frente a los significativos indicadores de pobreza, desempleo y saneamiento básico.

Lo descrito es complementado por el aporte investigativo de Ramírez y De Aguas (2017) en donde se destaca la importancia y se justifica un análisis como el presente, que explique las razones del 
rezago económico, social y cultural de las comunidades costeras alrededor de la actividad turística de sol y playa, como documento estratégico de consulta y base para propuestas tendientes a mejorar las condiciones de la población objeto de estudio por parte de las autoridades gubernamentales, siendo un factor de competitividad el turismo espontaneo o de sol y playa, transformador de la economía local y regional.

De allí que se tenga como propósito, determinar el impacto económico y sociocultural de la práctica turística de sol y playa en la subregión Golfo de Morrosquillo del Departamento de Sucre - Colombia, a partir de la realización de un diagnóstico del estado económico y sociocultural de la actividad y del análisis del comportamiento de los indicadores y categorías económicas y socioculturales asociadas.

Para Pérez et al. (2014), el turismo como actividad socioeconómica y cultural se define como un conjunto de actividades tendientes a la recreación que realizan personas, familias u organizaciones y que pueden implicar un desplazamiento o destino diferente al lugar habitual de residencia de los participantes. Lo anterior muestra un concepto amplio que cobija no solo una, sino variadas formas de turismo y zonas para el ejercicio del mismo.

Así, dentro de las diferentes modalidades de turismo se encuentra el turismo de sol y playa, que se caracteriza por encontrarse en zonas costeras que poseen playas con condiciones climáticas propicias para el goce de estas y que, en el curso del año, presentan muchos días soleados y temperaturas agradables. Al respecto, Varisco (2008) afirma que, en esta práctica se tienen en cuenta la población local, como receptora del turista de segunda residencia, con lo cual se busca caracterizar el primero e identificar orígenes, frecuencia, preferencias del segundo. El desarrollo económico local por otra parte, surge de tres temas comunes: la importancia de la innovación, las aglomeraciones productivas y la asociación. Por lo que esta teoría del desarrollo se ajusta a la visión del turismo, ya que permite integrar a la planificación a nivel de centros turísticos, con el objetivo de lograr el desarrollo regional y mejorar la calidad de vida de las comunidades receptoras. 
No obstante, no todo es positivo, el turismo de sol y playa genera un impacto sobre el medo ambiente dejando una huella ecológica significativa sobre los territorios, al respecto la Organización Mundial del Turismo [OMT] (2011) cuando afirma que:

Los impactos de un crecimiento turístico desordenado son notables sobre los recursos naturales y el medio ambiente, amenazando la sostenibilidad tanto ambiental como social y económica de dichas actividades. Las repercusiones se observan en las construcciones residenciales cerca de la zona costera, en la pesca y acuicultura, en la navegación, en el turismo, en el uso del suelo y por supuesto en el cambio climático. (p. 102)

Otro de los impactos relativos a esta modalidad de turismo es el económico, pues, no solo es generadora de ingresos, sino que además transforma la vocación productiva de las comunidades, que regularmente son pesqueras o agrícolas, por la dinámica propia de la actividad turística basada en el servicio y la explotación de los recursos naturales. Para Barros de Moraes (2013) esto no solo supone nuevos aprendizajes, sino que exige al nativo entrar en un mercado con altos estándares de exigencia en cuanto a la calidad y la experiencia y servicio de los visitantes, así como también de seguridad.

Este impacto involucra lo social y cultural, pues la transformación de la vocación productiva trae consigo cambios en las estructuras sociales de las comunidades, el turismo de sol y playa ha contribuido a la incorporación de nuevos hábitos gastronómicos, musicales, de vestuario, arquitectónicos y hasta religiosos, toda vez que ha facilitado la colonización de culturas foráneas y la afectación de las comunidades nativas en cuanto a su tradición e identidad.

Por tanto, el impacto socioeconómico y cultural del turismo de sol y playa sobre las comunidades nativas o raizales que se vinculan a la actividad bajo diferentes modalidades, es esencial para entender la dinámica del entorno, los cambios suscitados por cuenta del creciente auge de este servicio y las perspectivas en el corto y mediano plazo a razón de los planes de desarrollo municipales y departamental. En este orden de ideas, el Plan de Desarrollo "Sucre diferente" del gobernador del Departamento, Héctor Olimpo Espinosa Oliver (2020-2023) (Gobernación de 
Sucre, 2020), señala los desafíos del sector turístico, dentro de los cuales se destaca el mejoramiento de la infraestructura, la conectividad en los Municipios costeros, la formación bilingüe de los nativos y la formalización de su oferta turística (unidades de negocio), sin descartar la protección al medio ambiente y la articulación entre la academia, el gobierno y las comunidades dedicadas al servicio turístico, de donde se genera su sustento.

Así el impacto que generan fenómenos como el turismo en las comunidades costeras nativas es significativo y hace parte del nuevo desarrollo de dichos grupos humanos, al respecto, Rice (2000) señala que la sociedad y sus miembros más jóvenes se asocian en redes que en algunos casos reaccionan ante la tradición de sus mayores, explorando nuevas actividades, lo cual los lleva a cultivar nuevos valores y formas de producción.

Por lo tanto, los factores sociales son determinantes en el desarrollo económico, social y cultural del individuo, pues en ello se generan sus puntos de referencias en materia de apoyo e imagen desde el ejemplo y el sentido de la educación como factor de desarrollo personal y colectivo. Son los factores sociales aquellos impulsados desde la familia, la escuela, la comunidad y la sociedad en general y al tiempo los que llevan a valorar una actividad u otra generando una transformación de la vocación productiva.

De estos factores sociales, el familiar es el más importante, por tratarse de niños, jóvenes y adultos que viven en comunidad y por ser la familia el núcleo donde se forma la sociedad o el país. Para Ruiz (2001), éste conforma la primera instancia de formación del individuo y su importancia es esencial en cuanto a la introducción de valores y patrones de conducta, razón por la cual, su influencia en el desempeño productivo es capital, máxime si se trata de niños en formación. En este orden de ideas, los cuidadores o padres son los formadores iníciales de los niños, por lo tanto, las pautas de crianza son fundamentales en un cambio de prácticas productivas hacia el turismo como nueva actividad de sustento.

Por otra parte, el factor económico padece del impacto más relevante con el advenimiento de nuevas actividades productivas como el turismo de sol y playa. Desde el Programa de las Naciones Unidas para el Desarrollo [PNUD] (2015), las condiciones económicas constituyen uno de los 
factores que afectan en gran medida en la dinámica económica de las comunidades del litoral. Las medidas y políticas económicas trazadas por los gobiernos y las circunstancias del ingreso familiar traen consigo la reducción de subsidios; lo que genera la reducción en la contribución de los hogares a la educación de los hijos, recursos materiales insuficientes, salud deteriorada y violencia, lo cual obliga a los nativos a ofertar desde la informalidad servicios como el turístico.

En síntesis y desde la óptica del presente artículo y como resultado de la revisión bibliográfica adelantada como fundamento teórico y conceptual del fenómeno del turismo de sol y playa y su impacto socioeconómico y cultural en la forma de vida de los nativos de la subregión del Golfo del Morrosquillo en el Departamento de Sucre, el auge de la actividad turística en cuestión ha traído significativos cambios al modo de vida de las comunidades, destacando nuevas prioridades y transformando su vocación productiva por actividades asociadas al turismo. Así mismo, permitiéndoles una revaloración de sus costumbres ancestrales.

No obstante, la huella ecológica de la nueva actividad (turismo de sol y playa), plantea nuevos retos a estas comunidades y nuevas demandas en materia de infraestructura, conservación de recursos y formación del talento humano. De esta manera, el turismo de sol y playa es una realdad socioeconómica creciente y sostenible para las comunidades, siempre y cuando se prevean los impactos causados por esta y además se proyecte su crecimiento hacia una actividad formal que afecte positivamente la calidad de vida de los territorios costeros del departamento.

\section{Metodología}

El estudio corresponde a un paradigma interpretativo, puesto que, se destaca el como marco general de la investigación, toda vez que se trabajó con categorías socioculturales y de impacto sobre el territorio donde interactúan y por lo tanto hubo que comprender desde allí, puesto que, desde una visión holística del fenómeno, cada elemento cuenta y constituye el carácter de los sujetos frente al problema. Sobre éste, se plantea que "El paradigma interpretativo desarrolla interpretaciones de la vida social y el mundo desde una perspectiva social e histórica" (Pérez, 2004). 
En consecuencia, el estudio obedece a un enfoque cualitativo, este implica la utilización y recogida de una gran variedad de materiales - entrevista, experiencia personal, historias de vida, observaciones, textos históricos, imágenes, sonidos - "que describen la rutina y las situaciones problemáticas y los significados en la vida de las personas" (Rodríguez et al., 1996).

En el caso específico de las categorías socioculturales y de impacto sobre el territorio en el marco del fenómeno del turismo de sol y playa en la zona del litoral en el Departamento de Sucre. Ahora bien, en primer lugar, el tipo de investigación es de orden descriptivo observacional, los cuales se encargan de describir un fenómeno dentro de una población de estudio y conocer su distribución en la misma. En este tipo de estudios, no existe ninguna intervención por parte del investigador, la meta del investigador consiste en describir fenómenos, situaciones, contextos y sucesos; esto es, detallar cómo son y se manifiestan. Hernández et al. (2014) indican que con los estudios descriptivos se busca especificar las propiedades, las características y los perfiles de personas, grupos, comunidades, procesos, objetos o cualquier otro fenómeno que se someta a un análisis.

Del mismo modo se indica que, el presente estudio es de orden fenomenológico, puesto que la complejidad y variedad de fenómenos por estudiar no tiene límites, por lo que puede estudiarse todo tipo de emociones, experiencias, razonamientos o percepciones, es decir, puede centrase tanto en el estudio de aspectos de la vida ordinaria como también en fenómenos excepcionales. Asimismo, será de tipo transversal, como método no experimental para recoger y analizar datos en un momento determinado. Cabe anotar que, lo no experimental atañe a la búsqueda empírica y sistemática en la que el científico no posee control directo de las variables independientes, debido a que sus manifestaciones ya han ocurrido o a que son inherentemente no manipulables.

\section{Población}

Para el presente estudio, el grupo poblacional principal estuvo conformado por la totalidad de la población nativa laboralmente activa y asociada a las actividades turísticas de la zona de litoral en el Departamento de Sucre. En tal sentido y de acuerdo con el Programa de asistencia técnica a las comisiones regionales de competitividad realizado por el Ministerio de Comercio, Industria y Turismo (2018), existen dos cientos (200) empresarios turísticos constituidos legalmente, los cuales generan siete mil (7.000) empleos a nativos, por lo que se estima una población de siete mil 
nativos en los Municipios de Santiago de Tolú, San Onofre y Coveñas vinculados a actividades de turismo de sol y playa.

\section{Muestra}

Bajo un muestreo no probabilístico se seleccionó una muestra a partir de los siguientes criterios de inclusión: ser mayor de edad y estar vinculado a una o varias actividades turísticas de sol y playa, expresar voluntad de participar en el estudio, tener más de 2 años de pertenecer al sector turístico en territorio. De esta forma se obtuvo un grupo muestral de 135 personas cabezas de hogar distribuidos así: Municipio de San Onofre (25), Municipio de Coveñas (38), Municipio de Santiago de Tolú (72).

\section{Técnicas e instrumentos de recolección de datos}

Para la recolección de la información necesaria que permitiera los análisis requeridos por las categorías de estudio se utilizó un cuestionario de caracterización sociocultural y económica, constituido por cuatro (4) categorías: información básica de la localidad, aspectos sociales, aspectos económicos y aspectos culturales y treinta y un (31) ítems alrededor de cada una de las categorías, con múltiples opciones de respuesta. El instrumento fue validado por un experto.

\section{Resultados}

La caracterización económica, social y cultural de las comunidades (familias e individuos) dedicadas a la actividad del turismo de sol y playa en los Municipios de Santiago de Tolú, San Onofre y Coveñas, que constituyen la subregión del golfo del Morrosquillo en el Departamento de Sucre en el litoral Caribe, es una de las tareas centrales de un análisis de impacto de la actividad turística de sol y playa en el desarrollo y calidad de vida de dichas comunidades.

Esta caracterización implica necesariamente un contacto con las familias y las cabezas de hogar, quienes en su día a día derivan su sustento directa o indirectamente de las labores relacionadas con el turismo, en condiciones de informalidad y explotación indiscriminada de los recursos naturales. Cabe resaltar, que unida a la caracterización socioeconómica y cultural, se destaca el análisis de 
impacto económico de la actividad de turismo de sol y playa sobre dichas comunidades, lo cual es parte del análisis del presente estudio.

Por lo tanto, el proceso de caracterización socioeconómica y cultural que el presente estudio plantea a través de la aplicación del cuestionario de caracterización sociocultural y económica, arrojó resultados relacionados de forma gráfica y expuesta a continuación:

Como se expresa en la Figura 1, el uso de la vivienda está en un 94\% asociado a actividades productivas de tipo turístico como tiendas, estancos, restaurante u hospedajes en disposición de los turistas o visitantes. Además, el resultado refleja el carácter famiempresarial de las unidades de negocio disponibles desde los propios lugares de residencia de las comunidades.

\section{Figura 1}

Uso de la vivienda

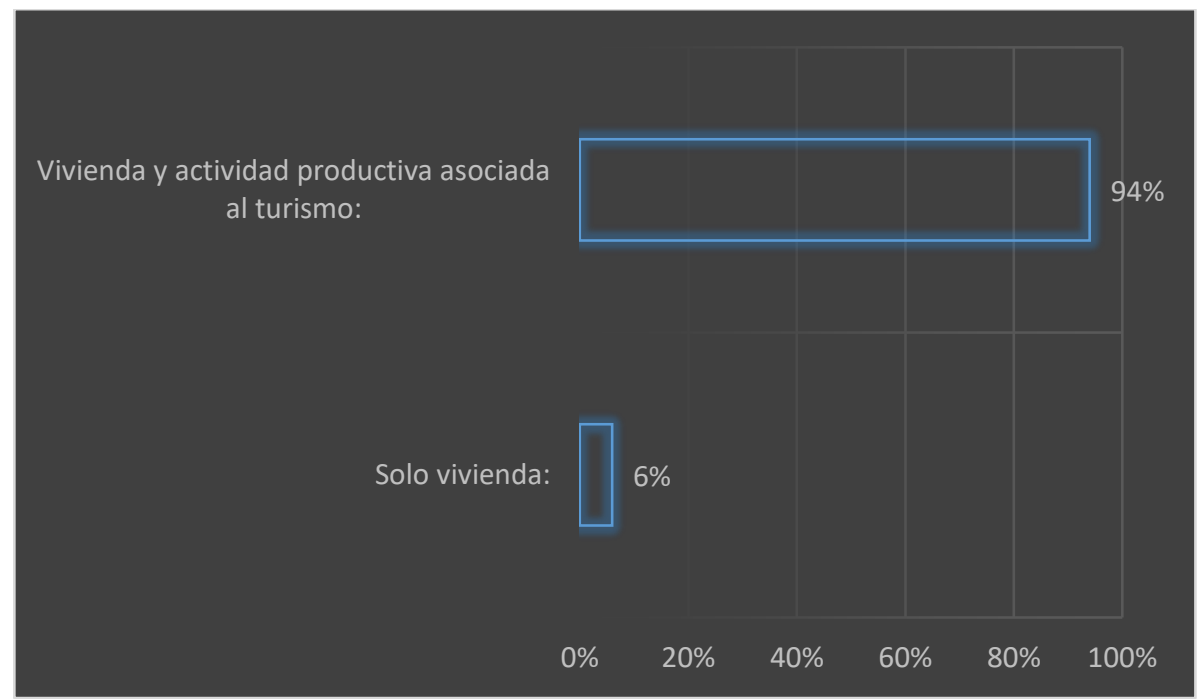

Fuente: grupo investigador (2020).

Como se expresa en la Figura 2, el 89\% de los consultados llevan más de 10 años habitando el predio, esto es, son residentes que tienen una tradición en el territorio, un arraigo que les ha permitido explotar el paisaje, y en la actualidad, realizar actividades asociadas al turismo de sol y playa en su mayoría de manera informal. 


\section{Figura 2}

Tiempo de residencia en el domicilio

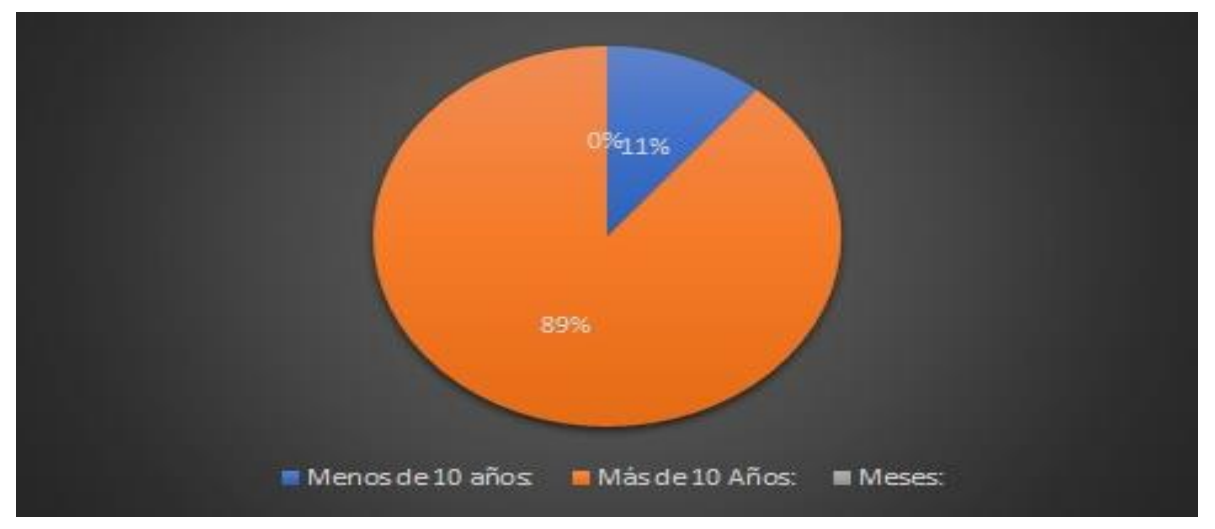

Fuente: grupo investigador (2020).

Como se expresa en la Figura 3, el 76\% de las familias consultadas pertenecen al estrato socioeconómico uno (1), lo cual las sitúa en condiciones de vulnerabilidad paradójicamente junto a las costas donde se da la actividad turística de sol y playa. Esto muestra claramente el carácter de la oferta turística nativa de las comunidades de los Municipios de Coveñas, Santiago de Tolú y San Onofre, con elementos del servicio precarios.

\section{Figura 3}

\section{Estrato socioeconómico}

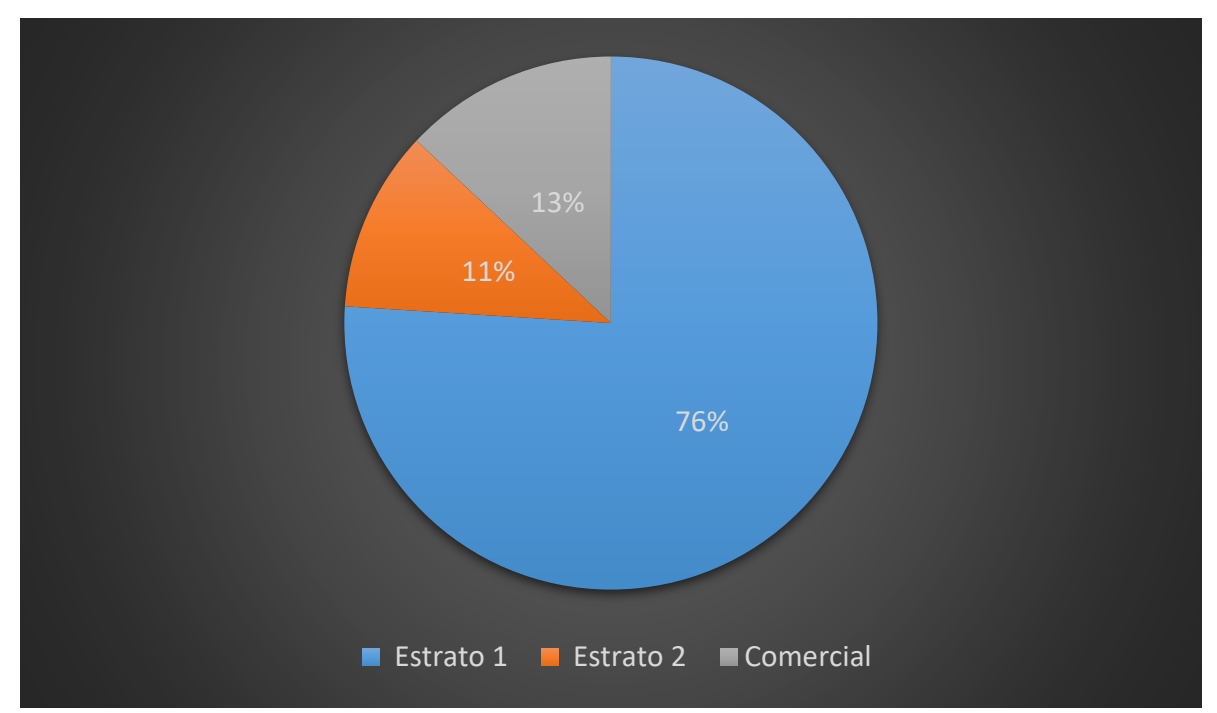

Fuente: grupo investigador (2020). 
Como se expresa en la Figura 4, el 64\% de las viviendas consultadas están habitadas entre una y dos familias y el $36 \%$ están habitadas por 3 o 5 familias, lo que muestra claramente una vida en comunidad y probable hacinamiento, a lo cual se suman las labores famiempresariales asociadas al turismo, lo que hace compleja la convivencia en dichas viviendas.

\section{Figura 4}

Número de familias que conviven en la vivienda

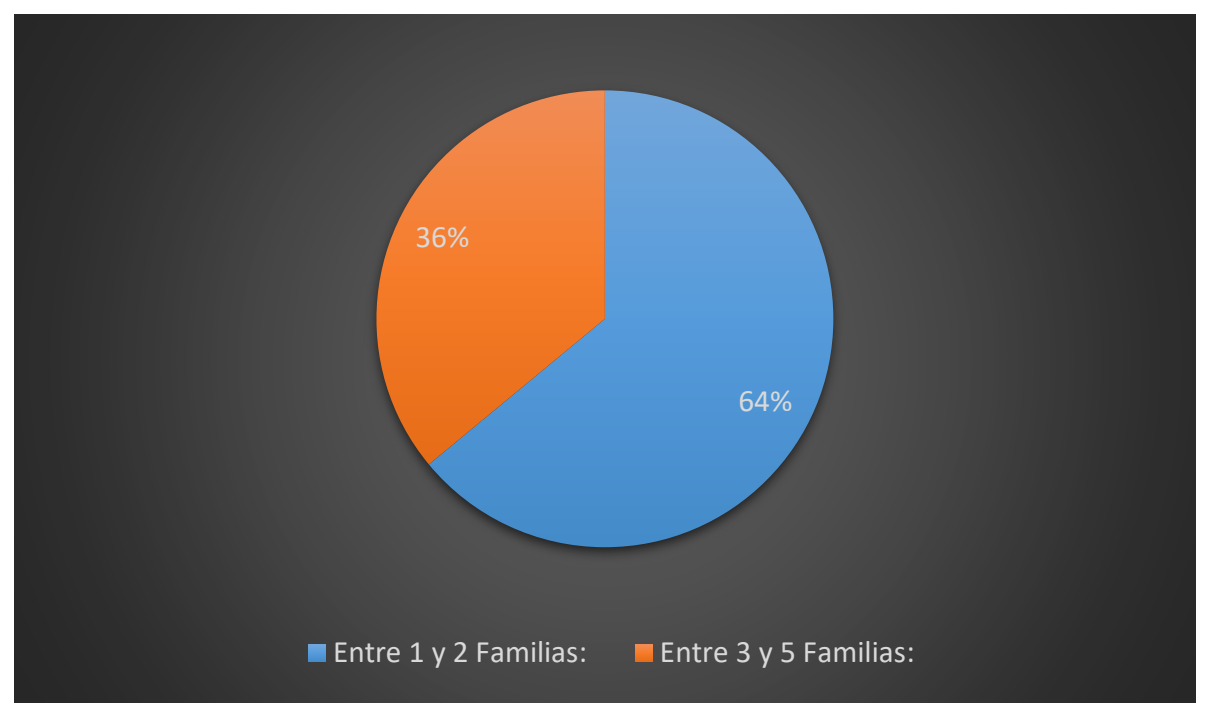

Fuente: grupo investigador (2020).

Como se expresa en la Figura 5, el $84 \%$ de las viviendas consultadas tienen como fuente principal de agua el pozo, lo cual indica que no tienen acceso al acueducto y por ende a alcantarillado y mucho menos al agua con calidad de potable para el consumo humano. Lo anterior da muestra de una de las carencias más sentidas de las comunidades nativas dedicadas a ejercer actividades de servicio turístico de sol y playa en los Municipios del Golfo de Morrosquillo. 


\section{Figura 5}

Principal fuente de agua

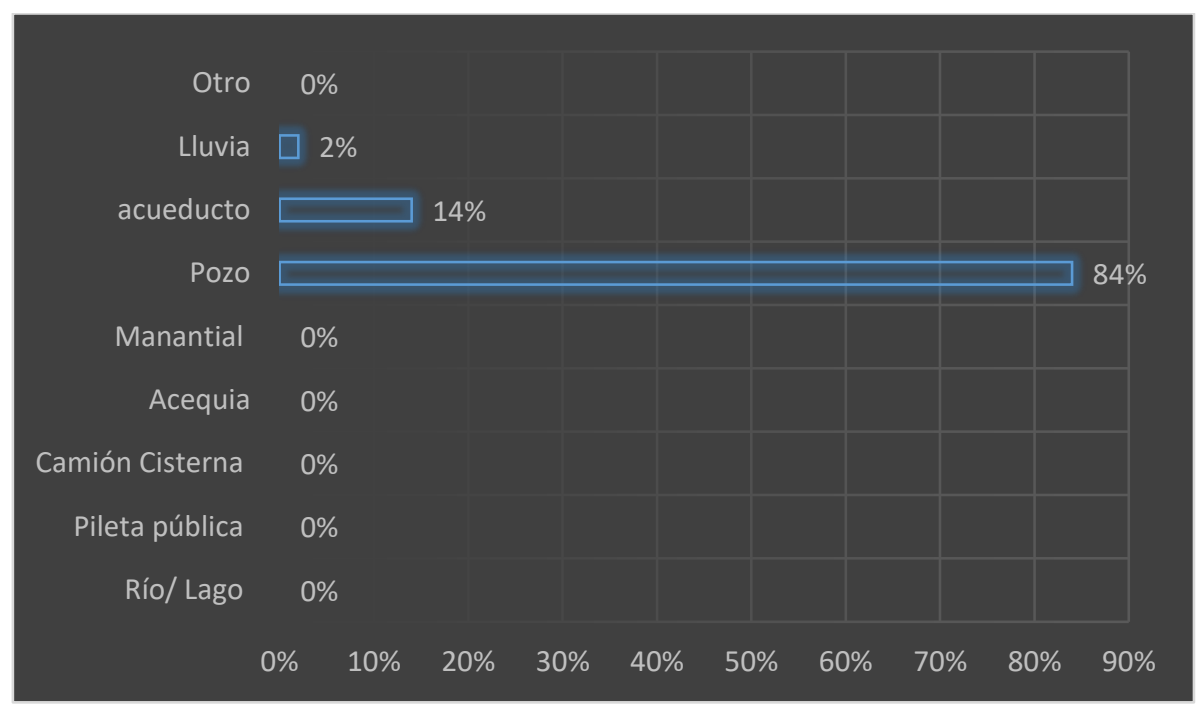

Fuente: grupo investigador (2020).

Como se expresa en la Figura 6, el $98 \%$ de los miembros de la familia no estudia en la actualidad, considera que es tarea de los menores, niños básicamente, los cuales asisten a las instituciones públicas de los Municipios, de lo cual se infiere que el nivel de escolaridad de los adultos no alcanza la media y en algunos casos existe analfabetismo entre los mayores.

\section{Figura 6}

\section{Formación en la familia}

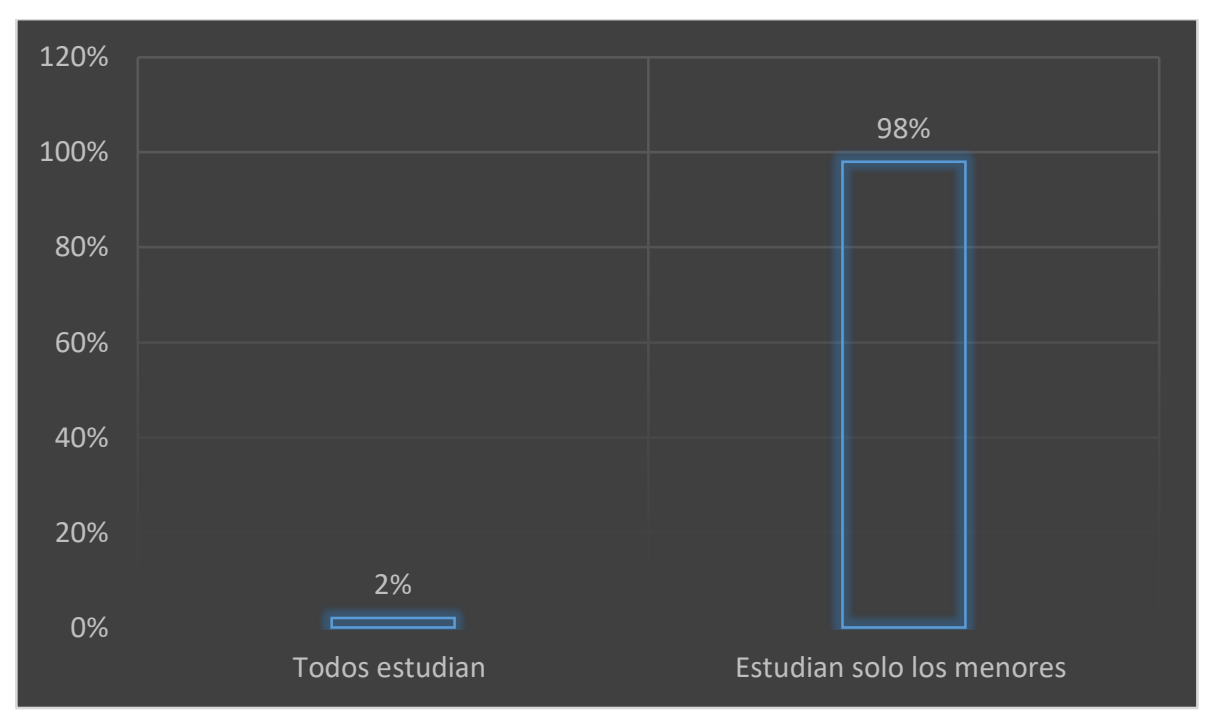

Fuente: grupo investigador (2020). 
Como se expresa en la Figura 7, el 98\% de los nativos dedicados a las actividades del turismo de sol y playa, ha sido capacitado en aspectos relacionados con dicha actividad. Cursos y seminarios cortos en atención al cliente, en gastronomía y manipulación de alimentos y prácticas de bioseguridad. No obstante, la oferta informal sigue siendo precaria en cuanto a estándares de calidad del servicio.

\section{Figura 7}

Capacitación en servicio turístico

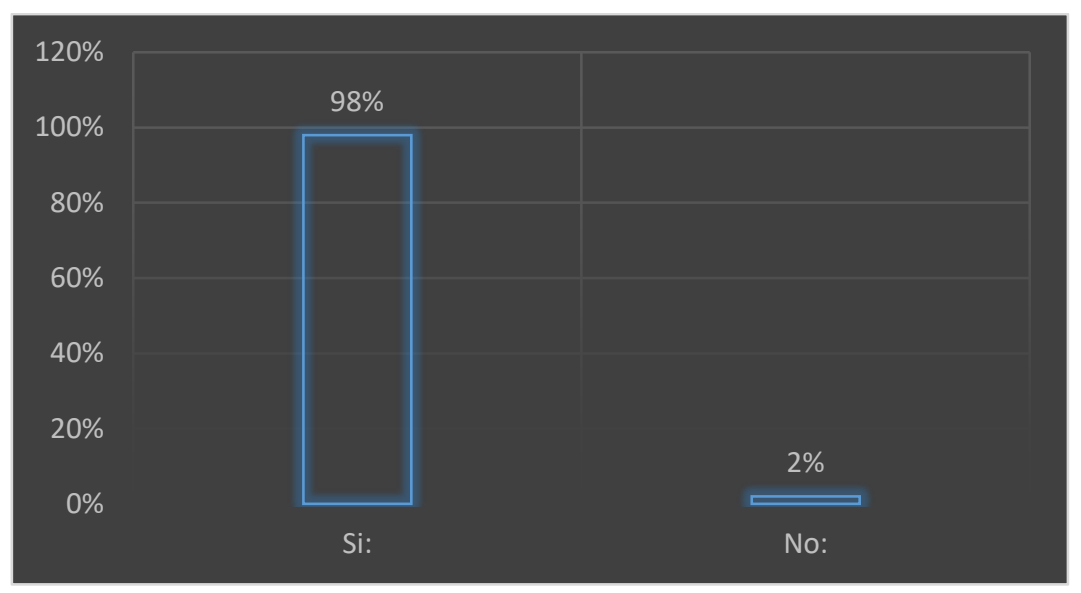

Fuente: grupo investigador (2020).

Como se expresa en la Figura 8, el 37\% de las familias consultadas, percibe ingresos entre 1 y 2 salarios mínimos, lo cual es relativamente bajo si se considera que son familias numerosas que viven de las actividades turísticas de sol y playa como su principal fuente de ingreso.

\section{Figura 8}

Ingresos familiares mensuales

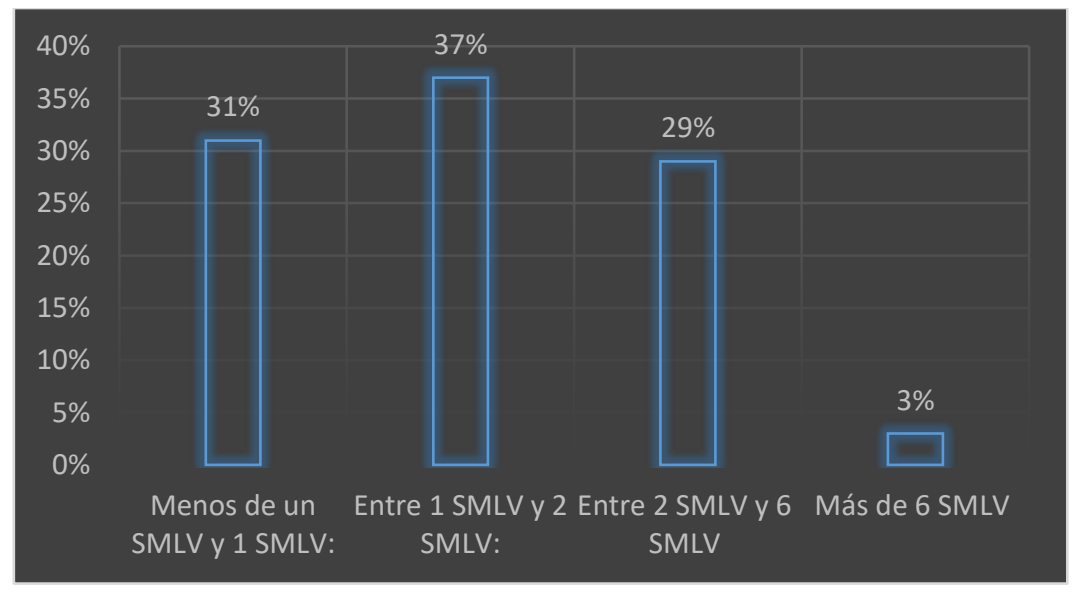

Fuente: grupo investigador (2020). 
Como se expresa en la Figura 9, el 96\% de las familias afirman que sus tradiciones y prácticas culturales constituyen un atractivo para los visitantes y que complementan el mar y el clima del Golfo. Pero más allá de lo anterior, se abre una fuente potencial de turismo cultural, aunado al turismo de sol y playa que revela la enorme riqueza turística de la zona.

\section{Figura 9}

Tradiciones culturales frente al turismo de sol y playa

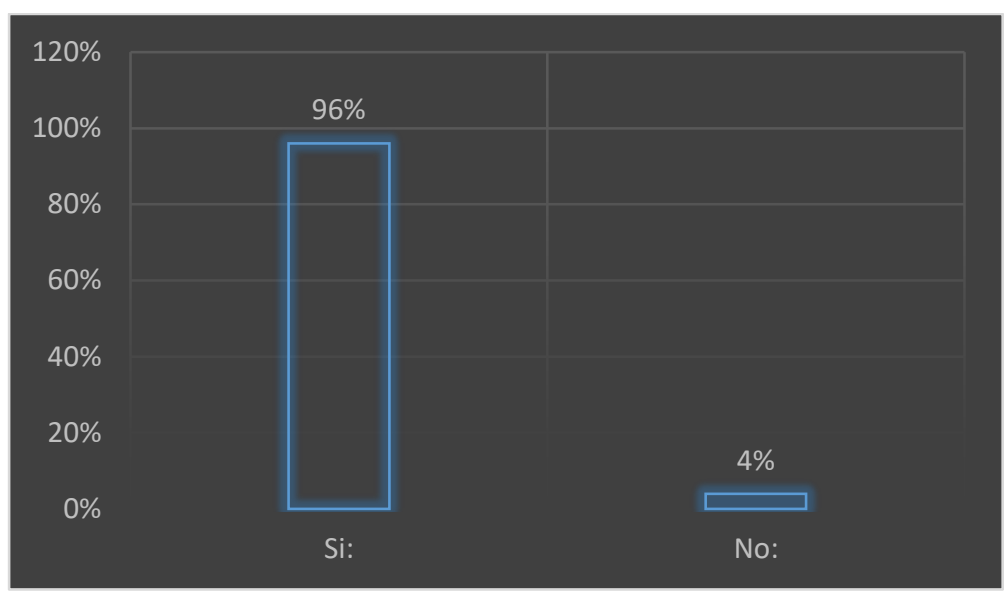

Fuente: grupo investigador (2020).

Como se expresa en la Figura 10, el 100\% de las familias afirman que identifican y valoran las tradiciones culturales propias de su región, además las ponen en práctica y las reconocen como atractivo turístico para propios y visitantes. Lo cual se corrobora en el resultado anterior.

\section{Figura 10}

Identificación y valoración de tradiciones culturales

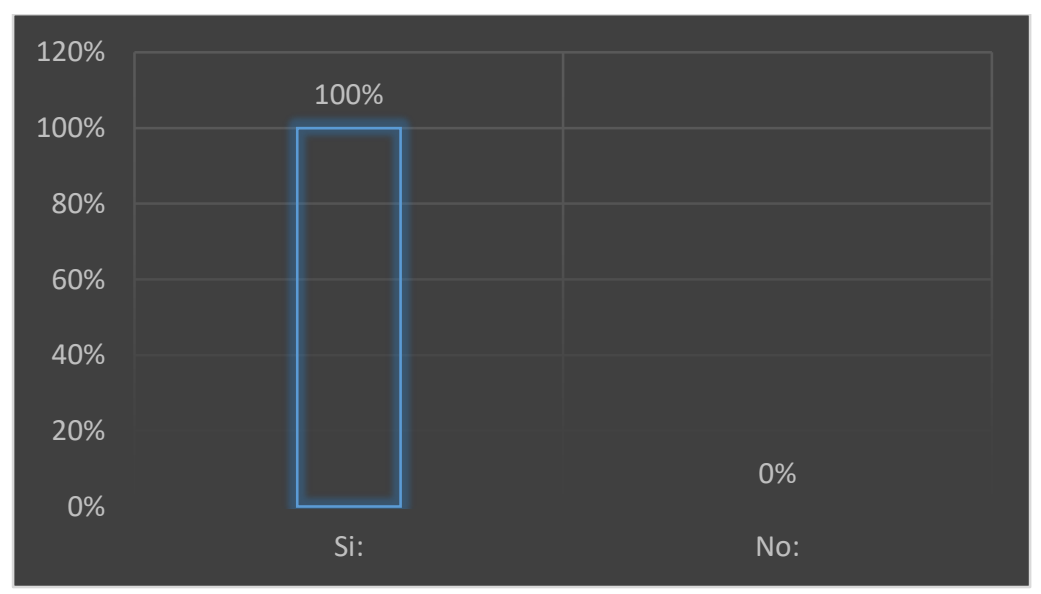

Fuente: grupo investigador (2020). 
Por otra parte, y como respuesta al segundo propósito del estudio, el comportamiento de los indicadores y categorías económicas y socioculturales asociadas a la actividad turística de sol y playa en la subregión Golfo de Morrosquillo se analizó a partir de:

\section{Vectores de desarrollo estratégico turístico del nivel departamental y municipal}

La actividad turística, sobretodo de sol y playa, es una de las ocupaciones más visibles y prometedoras del Caribe colombiano, de ella derivan su sustento miles de familias que histórica y tradicionalmente han derivado su sustento de las actividades conexas a la atención del turista en dichas playas. Por lo tanto, se ha constituido en uno de los sectores socioeconómicos más dinámicos en cuanto a generación de empleo, infraestructura y competitividad.

En este orden de ideas, la planeación estratégica expresada en los planes de desarrollo locales y departamentales, viene a concretar el interés y direccionamiento de las administraciones por el sector y el impacto de su desarrollo en los frentes sociales, económicos y culturales sobre las comunidades suscritas a la actividad. No obstante, el turismo de sol y playa, no alcanza aun el despliegue he impacto esperado, menos aun cuando se trata de las comunidades nativas, quienes han explotado el recurso natural de forma empírica y espontánea, siendo muchas veces explotados sistemáticamente por empresarios y capitales colonos.

Ochoa y Quintero (2017) revelan que el Departamento de Sucre y específicamente, la subregión del Golfo de Morrosquillo, con sus tres cabeceras municipales, San Onofre, Santiago de Tolú y Coveñas, concentra en esencia la mayor oferta de turismo de sol y playa del litoral, siendo reconocido como uno de los atractivos más importantes del país; generando oportunidades en materia comercial y económica en general para sus habitantes en materia de calidad de vida y desarrollo sostenible.

Lo anterior ha llevado a la incorporación estratégica de la actividad turística en los planes de desarrollo local y departamental, como es el caso del Plan territorial de desarrollo Municipio de Coveñas, “Coveñas es de todos” 2020-2023 (Alcaldía Municipio de Coveñas, 2020), en el cual se destaca la actividad turística como un eje estratégico de la dinámica económica, social y cultural del Municipio, el cual atrae la inversión nacional y extranjera y soporta en gran medida la 
generación de ingresos de cientos de familias dedicadas total o parcialmente a la actividad del turismo de sol y playa.

Así mismo, en el Plan de desarrollo territorial del Municipio de San Onofre, "Comprometida con San Onofre" (2016-2019) (Concejo Municipal de San Onofre - Sucre, 2016), apuntó al direccionamiento estratégico para aprovechar las potencialidades del entorno natural y el patrimonio cultural, con el consenso del sector privado y la comunidad para que el turismo sea una actividad competitiva y sostenible y se consolide como uno de los principales sectores económicos generadores de beneficios para el territorio.

En este sentido, el Municipio de Santiago de Tolú, en su Plan de desarrollo territorial "El Plan de todos por el cambio" (2016-2019) (Alcaldía Municipio de Santiago de Tolú, 2016), reconoce las dificultades que afronta la actividad turística del Municipio, que se ve afectada por los altos niveles de inseguridad, relacionados directamente con la oportunidad de inserción económica y social de los jóvenes, la ineficiente prestación con calidad y cobertura de los servicios públicos (acueducto, alcantarillado, aseo), la infraestructura vial, señalización, y de conectividad, y el cuidado y protección ambiental de los ecosistemas estratégicos que rodean el municipio. Es importante también el mejoramiento de la infraestructura de la ciudad y la capacidad de respuesta a emergencias. Estos aspectos son requisitos para que se pueda avanzar en el desarrollo de un clúster empresarial sostenible y con capacidad de crecimiento y de generación de trabajo decente.

En este sentido, el Municipio vive una realidad socioeconómica que impacta directamente a las comunidades que derivan su sustento del turismo de sol y playa, el cual esta agremiado en Asociación de Empresarios Turísticos del Golfo de Morrosquillo (ASETUR), asociación a la cual están asociados 55 establecimientos del sector hotelero y afines.

Así las cosas, la actividad turística de sol y playa en el Golfo del Morrosquillo constituye un sector importante y de alto impacto social, sin embargo la informalidad de las actividades comerciales y de servicios turísticos, la falta de promoción y posicionamiento de las playas, el bajo nivel de formación de los negocios alrededor de la cadena, el bajo nivel de calidad y la poca 
institucionalidad para la dinamización del sector, esto implica que no se logre transformar y mejorar la calidad de vida de sus habitantes, quienes carecen de condiciones óptimas de saneamiento, educación, ingresos dignos y empleo formal.

\section{Análisis circunstancial de vectores de desarrollo estratégico turístico y comportamiento socioeconómico}

En este orden de ideas, el comportamiento del sector turismo a lo largo del Golfo del Morrosquillo en el Departamento de Sucre, es la suma de oportunidades y dificultades en los últimos años, pues, porque pese a poseer un recurso natural invaluable como es el mar y un clima ideal, los problemas en materia de organización, infraestructura y corrupción, son obstáculos que han frenado el desarrollo de las comunidades.

De esta forma, la actividad turística mantiene una fuerte relación con aspectos de saneamiento básico, agua potable y alcantarillado, uno de los problemas históricos de la subregión y claves en la prestación de los servicios asociados al turismo de sol y playa. En el Plan de Desarrollo del municipio de Santiago de Tolú (2016-2019) (Alcaldía Municipio de Santiago de Tolú, 2016) se da a conocer que, el servicio de aseo tiene una cobertura del $100 \%$ en la zona urbana y un $60 \%$ en la zona rural, esto se debe a la dificultad para el ingreso del vehículo recolector en las comunidades que están más alejadas y por el mal estado de las vías de acceso a estas comunidades. El acueducto es surtido por una fuente de agua subterránea y las represas Villeros y Torrente, el Municipio tiene una cobertura de un $95 \%$ en redes.

Así mismo, indicadores como las vías de acceso al puerto, que son claves en la presencia de turistas en la subregión, encuentran dificultades. La Troncal del Caribe, que es una vía de carácter nacional cuenta con 14,1 km de longitud, se encuentra en su mayor parte deteriorada y es una vía estrecha, la cual provoca invasión de espacio público en época de temporada alta de turismo.

Como complemento al postulado anterior, se tiene la información institucional de la Alcaldía Municipio de Coveñas (2014) en donde se busca superar en materia de calidad de vida y el impacto por mejorar de la actividad turística de sol y playa sobre las comunidades que derivan sus ingresos de la misma, ya sea de forma directa e indirecta, lo cual fundamenta los niveles de competitividad 
necesarios hacia los que se orientan los vectores desde la política municipal y departamental en el plano económico, social y cultural.

En síntesis, los resultados muestran que el turismo de sol y playa ha generado un impacto importante en las comunidades costeras de los Municipios de Coveñas, Santiago de Tolú y San Onofre, transformando su vocación productiva y al tiempo demandando mayor acompañamiento de los gobiernos locales y departamentales, puesto que es una actividad generadora de empleos y con creciente proyección y potencial.

\section{Conclusiones}

El turismo de sol y playa como modelo y actividad económica es inseparable de la cultura, el territorio y la idiosincrasia de las comunidades costeras, estas se han adaptado a la dinámica de una actividad creciente en el mundo.

El cambio progresivo de vocación productiva, de pueblos agrícolas y pescadores a comunidades prestadoras de servicios turísticos, muestra un matiz en desarrollo en la zona del Golfo de Morrosquillo en el Departamento de Sucre, que tiene, entre otras consecuencias, la transformación del paisaje.

En el ámbito cultural, las comunidades son capaces de identificar y valorar sus tradiciones culturales y el potencial turístico de estas junto a los atractivos de sol y playa que constituyen la geografía de los Municipios costeros de Sucre.

Los indicadores económicos muestran que el turismo de sol y playa es una actividad con un mercado creciente, generadora de empleo e impulsadora de desarrollo social y cultural, que ha ganado importancia en el marco de los planes de desarrollo municipal y departamental.

El turismo de sol y playa como modelo de producción recoge la experiencia exitosa de países como España, Estados Unidos y México, donde ha demostrado importantes efectos en el desarrollo 
económico de las poblaciones costeras, lo cual fundamenta las acciones de promoción y apoyo a esta modalidad de turismo en el Departamento de Sucre.

Las condiciones de vulnerabilidad de las familias dedicadas a la actividad turística en el Golfo del Morrosquillo, es uno de los obstáculos que impiden un desarrollo y formalización de dicha actividad, logrando alcanzar estándares de calidad en el servicio y mejorar ostensiblemente sus ingresos y con ello su calidad de vida.

En este sentido, las recomendaciones están orientadas al desarrollo de proyectos para el fortalecimiento del sector turístico en la subregión, que históricamente ha estado sobrediagnosticada por los planes de gobiernos locales y departamentales de turno, pero poco intervenida de forma integral en sus frentes sustantivos: saneamiento, infraestructura, capacitación y visibilización.

El saneamiento como medida básica de calidad de vida, pero también como base de un servicio turístico competitivo. La infraestructura sostenible como parte de la oferta turística de sol y playa, la capacitación como parte de la transformación y cualificación del talento humano nativo y la visibilización como estrategia integral de posicionamiento en el mercado nacional e internacional.

\section{Referencias}

(1) Alcaldía Municipio de Coveñas - Sucre. (2014). Nuestro Municipio. Información general. http://www.covenas-sucre.gov.co/

(2) Alcaldía Municipio de Coveñas - Sucre. (2020). Programa de Gobierno 2020-2023 “Coveñas es de todos". http://www.covenas-sucre.gov.co/planes/programa-de-gobierno-2020-2023covenas-es-de-todos

(3) Alcaldía Municipio de Santiago de Tolú. (2016). Plan de Desarrollo Territorial. El plan de todos por el cambio 2016-2019. https://www.santiagodetolusucre.gov.co/Transparencia/PlaneacionGestionyControl/Plan\%20de\%20Desarrollo\%20Terri torial\%202016-2019.pdf 
(4) Alcaldía Municipio de Tolú - Sucre. (2014). Nuestro Municipio. Información general. Disponible en http://santiagodetolu-sucre.gov.co/MiMunicipio/Paginas/Economia.aspx

(5) Aguilera, M. (2005). La economía del departamento de sucre: ganadería y sector público. Documentos de trabajo sobre economía regional, (63).

(6) Amaya, C., Sosa, A., Moncada, P. (2017). Determinantes de competitividad turística en destinos de sol y playa mexicanos. Región y sociedad, 29(68), 279-315. https://doi.org/10.22198/rys.2017.68.a205

(7) Barros de Moraes, L. (2013). Impactos del turismo de sol y playa en el litoral sur de Sergipe, Brasil. Estudios y Perspectivas en Turismo, 22(3), 526-545. https://www.redalyc.org/pdf/1807/180726463008.pdf

(8) Beltrán, L. y Gómez, E. (2018). Medición de los objetivos de desarrollo del milenio como baremo de desarrollo social en Sucre, Colombia. Económicas CUC, 39(1), 153-166. http://dx.doi.org/10.17981/econcuc.39.1.2018.10

(9) Concejo Municipal de San Onofre - Sucre. (2016). Plan de desarrollo territorial 2016-2019 "Comprometida con San Onofre". https://sanonofresucre.micolombiadigital.gov.co/sites/sanonofresucre/content/files/000062/3 068_acuerdo-0012016.pdf

(10) García, A y Albuquerque, F. (2003). El turismo cultural y el de sol y playa: ¿sustitutivos o complementarios? Cuadernos de Turismo, (11), 99-105. https://revistas.um.es/turismo/article/view/19581

(11)Gobernación de Sucre. (2020). Plan de Desarrollo Sucre Diferente 2020 -2023. http://www.sucre.gov.co/planes/plan-de-desarrollo-departamental-sucre-diferente-sin

(12) Hernández, R., Fernández, C. y Baptista. P. (2014). Metodología de la investigación. Mc Graw Hill.

(13) Mercado, T., Pacheco, C. y Rojas, C. (2015). Estructura empresarial del sector turístico en los Municipios de Tolú y Coveñas. Desarrollo Gerencial, 7(2), 136-152. http://dx.doi.org/10.17081/dege.7.2.1185

(14) Ministerio de Comercio, Industria y Turismo. (2018). Estrategia para la coordinación y seguimiento de las comisiones regionales de competitividad. 
http://www.competitivas.gov.co/sites/default/files/documentos/estrategia_crc_20162018.pdf

(15) Ochoa, M. y Quintero, J. (2017). El turismo como factor de competitividad en el desarrollo socioeconómico del municipio de Coveñas, departamento de Sucre. [Tesis de Maestría]. Universidad Tecnológica de Bolívar. https://biblioteca.utb.edu.co/notas/tesis/0073559.pdf

(16) Organización Mundial de Turismo [OMT]. (2011). El turismo: un fenómeno económico y social. https://www.unwto.org/es/turismo

(17) Ortiz, J. y Peralta, P. (2019). El Turismo de sol y playa: Impacto turístico en los ecosistemas de la comuna Ayangue, para mejorar la gestión de la actividad turística en la provincia de Santa Elena. Revista Científica y Tecnológica UPSE, 6(2), 82-90. http://doi.org/10.26423/10.26423/rctu.v6i2.494

(18) Pérez, G. (2004). Investigación cualitativa. Retos e interrogantes. I. Métodos. La Muralla S.A.

(19)Pérez, V., Guerrero, F., González, M., Pérez, F. y Caballero, R. (2014). La sostenibilidad de los destinos cubanos de turismo de naturaleza: un enfoque cuantitativo. Tourism \& Management Studies, 10(2), 32-40. https://www.redalyc.org/pdf/3887/388743882005.pdf

(20) Programa de las Naciones Unidas para el Desarrollo [PNUD]. (2015). Panorama general. Informe sobre Desarrollo Humano 2015. Trabajo al servicio del desarrollo humano. Communications Development Incorporated. http://hdr.undp.org/sites/default/files/2015_human_development_report_overview_-_es.pdf

(21) Ramírez, J. y De Aguas, J. (2017). Escalafón de la competitividad de los departamentos de Colombia 2017. Comisión Económica para América Latina y el Caribe (CEPAL). https://repositorio.cepal.org/bitstream/handle/11362/43156/1/S1800010_es.pdf

(22) Rice, P. (2000). Adolescencia. Desarrollo, relaciones y cultura. Prentice Hall.

(23) Rodríguez, G., Gil, J. y García, E. (1996). Metodología de la investigación cualitativa. Ediciones Aljibe.

(24)Romero, E. (2017). Estrategia para posicionar el golfo de Morrosquillo como destino turístico: propuesta de un modelo de desarrollo local. [Tesis de maestría]. Universidad Tecnológica de Bolívar. https://biblioteca.utb.edu.co/notas/tesis/0070433.pdf

(25)Ruiz, C. (2001). Factores familiares vinculados al bajo rendimiento. Revista Complutense de Educación, 12(1), 81-113. https://revistas.ucm.es/index.php/RCED/article/viewFile/RCED0101120081A/16850 
Impacto socioeconómico y cultural del turismo de sol y playa en el Golfo de Morrosquillo 2016 - 2020 Anddy Katherine Sierra Márquez; Licette Estela Ramos Pérez; Mario Fernando Zubiría Lara

(26) Varisco, C. (2008). Desarrollo turístico y desarrollo local: La competitividad de los destinos turísticos de sol y playa. [Tesis de Maestría]. Universidad Nacional de Mar del Plata. http://nulan.mdp.edu.ar/550/1/varisco_c.pdf

Cómo citar este artículo: Sierra, A., Ramos, L. y Zubiría, M. (2021). Impacto socioeconómico y cultural del turismo de sol y playa en el Golfo de Morrosquillo 2016 - 2020. Tendencias, 22(2), 239-263. https://doi.org/10.22267/rtend.212202.175 